\title{
Prospecção Tecnológica Acerca da Produção e da Aplicação de Biofertilizantes no Cultivo de Leguminosas
}

\author{
Technological Prospection in the Scope of the Production and \\ Application of Biofertilizers Applied in the Cultivation of Legumes
}

\author{
Erika Matias da Silva ${ }^{1}$ \\ Adrielle Firmino da Silva ${ }^{1}$ \\ Jenivaldo Lisboa de Araújo ${ }^{2}$ \\ ${ }^{1}$ Universidade Estadual de Alagoas, Palmeira dos Índios, AL, Brasil \\ ${ }^{2}$ Escola Estadual Muniz Falcão, Cacimbinhas, AL, Brasil
}

\begin{abstract}
Resumo
Com o intuito de promover um mapeamento dos trabalhos relacionados à produção e à aplicação de biofertilizantes no cultivo de leguminosas, foram utilizados bancos de patentes (INPI, WIPO e Espacenet) e de artigos (Periódicos), de forma a avaliar o panorama do estágio atual no desenvolvimento científico e tecnológico nessa área. A pesquisa demonstrou a liderança da China, tanto na produção científica quanto patentária voltada ao tema. A partir do estudo nas diversas bases, é notável que tanto o número de patentes quanto o de artigos publicados relacionados à área investigada ainda sejam limitados, demonstrando a necessidade de maiores estudos e investigações para ampliação do aporte tecnológico acerca da aplicação de biofertilizantes em leguminosas.
\end{abstract}

Palavras-chave: Tecnologia Agroecológica. Agricultura. Sustentabilidade.

\begin{abstract}
Aiming to promote a mapping of works related to the production and application of biofertilizers in the cultivation of legumes, used databases (INPI, WIPO and Espacenet) and articles (Periodicals), in order to evaluate the panorama or the current study program in progress and technological development in this area. Research has shown China's leadership both in scientific production and in the patent on the topic. From the study of several bases, the number of patents on published articles related to the still limited area is notable, demonstrating the need for further studies and investigations to expand a technological set related to the application of biofertilizers in legumes.
\end{abstract}

Keywords: Agroecological Technology. Agriculture. Sustainability.

Área Tecnológica: Agricultura Sustentável. Produção de Biofertilizantes. 


\section{Introdução}

A agricultura é uma das atividades humanas que mais contribui para a crescente quantidade de poluentes pelo uso excessivo de agroquímicos nocivos ao homem e a todo o meio ambiente (PRAKASH; ARORA, 2019). Essa situação tem como resultado um aumento de precauções da parte dos consumidores, que, além de afetados pela má qualidade dos insumos, pagam mais caro pelos produtos devido ao manejo do produtor (VASSILEV et al., 2015). Nesse sentido, os processos de lixiviação de nitrogênio, volatilização de amônia e escoamento de fósforo geram uma crescente preocupação diante do impacto ambiental passível de ser causado pela atividade agrícola (DADRASAN et al., 2015). Apesar de o nitrogênio e o fósforo serem os principais nutrientes responsáveis pelo crescimento das plantas em todo o mundo (BLAISE et al., 2005).

Com a crescente demanda de produtos agrícolas e a necessidade de uma redução tênue de fertilizantes sintéticos e pesticidas, a busca por técnicas alternativas vem sendo alvo de diversas pesquisas. Entre essas tecnologias estão presentes os biofertilizantes, os quais surgem diante de uma crescente consciência ecológica por parte dos consumidores e dos produtores rurais, preocupados com a qualidade de vida, o que contribui para a formação de sistemas agroecológicos (ARAÚJO; GOMES; SOUZA, 2014). O biofertilizante é um adubo, geralmente líquido, formado pela decomposição de esterco e restos de cultura em um recipiente que pode estar, ou não, em contato com o ar (ARAÚJO; GOMES; SOUZA, 2014). Seu uso na agricultura visa a garantir a sustentabilidade sem a perda de produtividade, obtendo altos rendimentos agrícolas e, ao mesmo tempo, preservando o meio ambiente, além de garantir um baixo custo e com consumo mínimo de fertilizantes e quaisquer outros produtos químicos, desempenhando, assim, um papel importante na manutenção da fertilidade do solo (GONZÁLEZ et al., 2016).

Mesmo com os novos meios de tecnologia de produção, os pesquisadores ainda fazem uso de adubação por meio de estercos de diversas espécies e resíduos orgânicos. Dentro do setor voltado para essa indústria, ganha destaque o uso de microrganismos como bactérias (AMBROSIO; ORTIZ-MARQUEZ; CURATTI, 2017), algas unicelulares (NUNNERY; MEVERS; GERWICK, 2010) e fungos (IGIEHON; BABALOLA, 2017) aplicados em sua produção. Diante do exposto, propõe-se que uma tecnologia vinculada a esse conceito seja a inclusão de microrganismos nas sementes (inoculação), como fungos micorrízicos, bactérias fixadoras de $\mathrm{N}$ e/ou solubilizadores de fósforo, que produzem efeitos aditivos de particular importância na produtividade da lavoura e sua melhor qualidade fitossanitária, além de aumentar o conteúdo de matéria orgânica no solo (NODA, 2009).

O cultivo de leguminosas (família: Fabaceae) como fonte de alimento vem tornando-se comum, devido às suas proteínas, minerais e outras moléculas bioativas, dotando-as de um grande valor comercial. São caracterizadas pela presença de grãos em vagens e por possuírem pouca gordura e muita fibra, sendo fontes de vitaminas $\mathrm{C}$, do complexo $\mathrm{B}$ e $\mathrm{K}$, e de ácido fólico. Apresentando em sua composição carboidratos complexos, minerais como potássio, fósforo, magnésio, zinco, ferro, cálcio e pouca quantidade de colesterol e sódio, estão presentes no cotidiano na forma de alimentos como feijão, lentilha, grão-de-bico, soja, ervilha, fava e amendoim.

Nesse sentido, o presente trabalho pretende mostrar o estado da arte dos biofertilizantes usados no cultivo de leguminosas. Demonstrando novas técnicas e manejos, com o intuito de avaliar o panorama do estágio atual e de identificar as tendências no desenvolvimento científico e tecnológico, serão apontados os principais "players" de mercado e os pesquisadores relacionados à área. 


\section{Metodologia}

Foi feita uma prospecção tecnológica entre os meses de março e julho de 2020 a partir da análise de artigos científicos e patentes nacionais e internacionais. A busca por patentes foi realizada utilizando-se três bases de dados, sendo estas: European Patent Office (EPO/Espacenet), Instituto Nacional da Propriedade Industrial (INPI) e World Intellectual Property Organization (WIPO). Enquanto a pesquisa por artigos ocorreu com uso do Portal Periódicos disponibilizado pela CAPES/MEC e da base de dados Scielo (Scientific Eletronic Library Online).

Inicialmente, as pesquisas foram feitas pelo método de busca combinada (avançada) na primeira página (front page) em todas as bases escolhidas, utilizando termos característicos ao material e sua aplicação no cultivo de leguminosas. Foram realizadas três etapas de filtragem de resultados, em que a primeira consistiu no uso dos termos 1 , havendo um segundo filtro com a combinação dos termos 1, 2 e 3, todos estes descritos nas Tabelas 1 e 2 . Os termos utilizados para realizar as pesquisas não necessitaram de tradução para a língua inglesa, uma vez que apresentam os mesmos radicais em ambos os idiomas, sendo eles: (fert* or biofert*); (legum*) e (prod* or plant* or cult*).

Após a realização das buscas procedeu-se a uma análise individual dos trabalhos encontrados, de modo a identificar aqueles que apresentassem uma descrição sobre o uso de biofertilizantes no cultivo de leguminosas, denominando-se esse grupo como "patentes de interesse". A Tabela 1 mostra, respectivamente, os resultados obtidos por meio dos bancos de patentes do EPO/Espacenet, WIPO e INPI, ficando visível a necessidade de somente um filtro na base INPI, enquanto na Tabela 2 foram utilizados os três termos disponíveis diante da quantidade de resultados retornados.

Tabela 1 - Pesquisa por combinações de palavras-chave nos sites EPO/Espacenet, WIPO e INPI

\begin{tabular}{ccccccc} 
Termo 1 & Termo 2 & Termo 3 & EPO & INPI & WIPO & $\begin{array}{c}\text { Patentes DE } \\
\text { INTERESSE }\end{array}$ \\
\hline biofert* or fert* & - & - & 10.000 & 15 & 222571 & 0 \\
biofert* or fert* & legum* & cult* or prod* or plant* & 482 & - & 462 & $191^{(*)}$ \\
\hline
\end{tabular}

(*) Dados relacionados a duas bases de dados.

Fonte: Elaborada pelos autores deste artigo (2020)

Tabela 2 - Pesquisa por combinações de palavras-chave no Portal Periódicos

\begin{tabular}{|c|c|c|c|c|c|}
\hline \multirow{2}{*}{\multicolumn{3}{|c|}{ PALAVRAS-CHAVE UTILIZADAS }} & \multicolumn{2}{|c|}{ ARtigos tOtAis } & \multirow{2}{*}{ ARTIGOS DE INTERESSE } \\
\hline & & & Periódicos & SCIELO & \\
\hline biofert* or fert* & legum* & cult* or prod* or plant* & 167 & 400 & $22^{(*)}$ \\
\hline
\end{tabular}

(*) Dados relacionados a duas bases de dados.

Fonte: Elaborada pelos autores deste artigo (2020) 
Em seguida, procedeu-se a uma pesquisa patentária complementar no banco de dados da WIPO utilizando a Classificação Internacional de Patentes (CIP) (IPC - International Patent Classification) descritas na Tabela 3, como forma de ampliar o escopo da pesquisa acerca de produtos desenvolvidos especificamente para leguminosas. A busca ocorreu com uso combinado da classificação A01G com outros IPCs relacionados à produção de biofertilizantes e adubos (Tabela 4). Essa associação foi feita com o intuito de limitar as patentes resultantes da pesquisa daquelas cujo objeto de interesse estivesse relacionado à aplicação na horticultura.

Tabela 3 - Relação de IPCs utilizadas durante busca no banco de dados da WIPO

\begin{tabular}{|c|c|}
\hline IPC & DESCRIÇÃO \\
\hline A01G & Horticultura; cultivo de vegetais, flores, arroz, fruta, vinhas, lúpulo ou alga; e silvicultura. \\
\hline C05B & Adubos fosfatados. \\
\hline $\mathrm{C05C}$ & Fertilizantes nitrogenados. \\
\hline C05F $17 / 50$ & Tratamento anaeróbio e aeróbio ou vermicompostagem e tratamento aeróbio. \\
\hline C05F $1 / 00$ & Fertilizantes feitos de cadáveres de animais, ou partes deles. \\
\hline C05F 3/00 & Fertilizantes de excrementos humanos ou animais. \\
\hline $\mathrm{C} 05 \mathrm{~F} 3 / 02$ & Guano. \\
\hline $\mathrm{C} 05 \mathrm{~F} 3 / 04$ & Adubos de massas fecais humanas. \\
\hline $\mathrm{C} 05 \mathrm{~F} 5 / 00$ & Fertilizantes de resíduos de destilaria, melaço, vinagre, planta de açúcar ou resíduos parecidos. \\
\hline $\mathrm{CO5F} 7 / 00$ & Fertilizantes de águas residuais, lodo de esgoto, lodo do mar, lodo ou massas semelhantes. \\
\hline C05F 9/00 & Fertilizantes de resíduos domésticos ou urbanos. \\
\hline C05F 9/04 & Composto biológico. \\
\hline C05F $11 / 02$ & Fertilizantes de turfa, carvão marrom ou depósitos vegetais semelhantes. \\
\hline C05F $11 / 04$ & Terra de horticultura de turfa. \\
\hline C05F $11 / 10$ & Fertilizantes contendo vitaminas ou hormônios vegetais. \\
\hline
\end{tabular}

Fonte: Elaborada pelos autores deste artigo (2020)

Tabela 4 - Pesquisa patentária no banco de dados da WIPO

$\begin{array}{cccc}\text { IPC } 1 & \text { IPC } 2 & \text { PATENTES TOtaIS } & \text { PATENTES DE INTERESSE } \\ \text { C05B } & \text { A01G } & 288 & 10 \\ \text { C05C } & \text { A01G } & 385 & 7 \\ \text { C05F } 1 / 00 & \text { A01G } & 124 & 16 \\ \text { C05F 3/00 } & \text { A01G } & 449 & 27 \\ \text { C05F 3/02 } & \text { A01G } & 14 & 2 \\ \text { C05F 3/04 } & \text { A01G } & 16 & 1 \\ \text { C05F 5/00 } & \text { A01G } & 308 & 10 \\ \text { C05F 7/00 } & \text { A01G } & 204 & 2 \\ \text { C05F 9/00 } & \text { A01G } & 328 & 8\end{array}$




\begin{tabular}{cccc} 
IPC $\mathbf{1}$ & IPC 2 & Patentes totals & Patentes De INTERESSE \\
C05F 9/04 & A01G & 151 & 1 \\
C05F 11/02 & A01G & 546 & 3 \\
C05F 11/04 & A01G & 148 & 1 \\
C05F 11/10 & A01G & 129 & 4 \\
C05F 17/50 & A01G & 279 & 2 \\
\hline
\end{tabular}

Fonte: Elaborada pelos autores deste artigo (2020)

\section{Resultados e Discussão}

As combinações entre o IPC A01G e os códigos C05F 1/00 e C05F 3/00 demonstram que a grande maioria dos produtos tem como matéria-prima principal: as fezes, excrementos ou algum tipo de matéria animal. Enquanto a busca combinada com C05F 5/00 mostra uma tendência na pesquisa por fertilizantes derivados de resíduos de destilaria, melaço, usinas de açúcar ou resíduos semelhantes.

A partir dessas classificações, pode-se verificar que há muitos trabalhos relacionados ao uso generalizado de biofertilizantes, havendo uma pequena parcela voltada especificadamente para a produção desses insumos no cultivo de leguminosas, sendo ainda menores aqueles voltados para uma espécie específica de leguminosa.

Os dados presentes na Figura 1 apresentam a China como maior produtora de tecnologia voltada para a indústria de biofertilizantes, com um total de 91 patentes. Seu predomínio perante os demais países pode ser explicado por sua cultura empreendedora e pela elevada densidade populacional, o que torna necessária a busca por alternativas que aumentem o rendimento de seus cultivos, de maneira a prover o sustento da nação.

A busca no banco de dados da WIPO mostrou a existência de três picos com maior número de publicações voltadas para o estudo de biofertilizantes entre os anos 2003, 2009 e 2014 a 2020, havendo algumas oscilações nesse período (Figura 2). Tais resultados foram associados aos esforços dos países protagonistas no cenário mundial de patentes em busca de economias sustentáveis, juntamente ao impulso chinês voltado para a manutenção no desenvolvimento de fertilizantes sintéticos (ABSOLO, 2017). Já que o predomínio do mercado asiático como terceiro maior no ramo de biofertilizantes, e a perspectiva de atingir o segundo maior crescimento até o ano de 2020, revela o impacto causado por medidas tomadas por estes países e sua importância no desenvolvimento deste setor (BUSINESS WIRE, 2018). 
Figura 1 - Principais países depositantes de patentes retornados a partir de buscas na WIPO, INPI e Espacenet

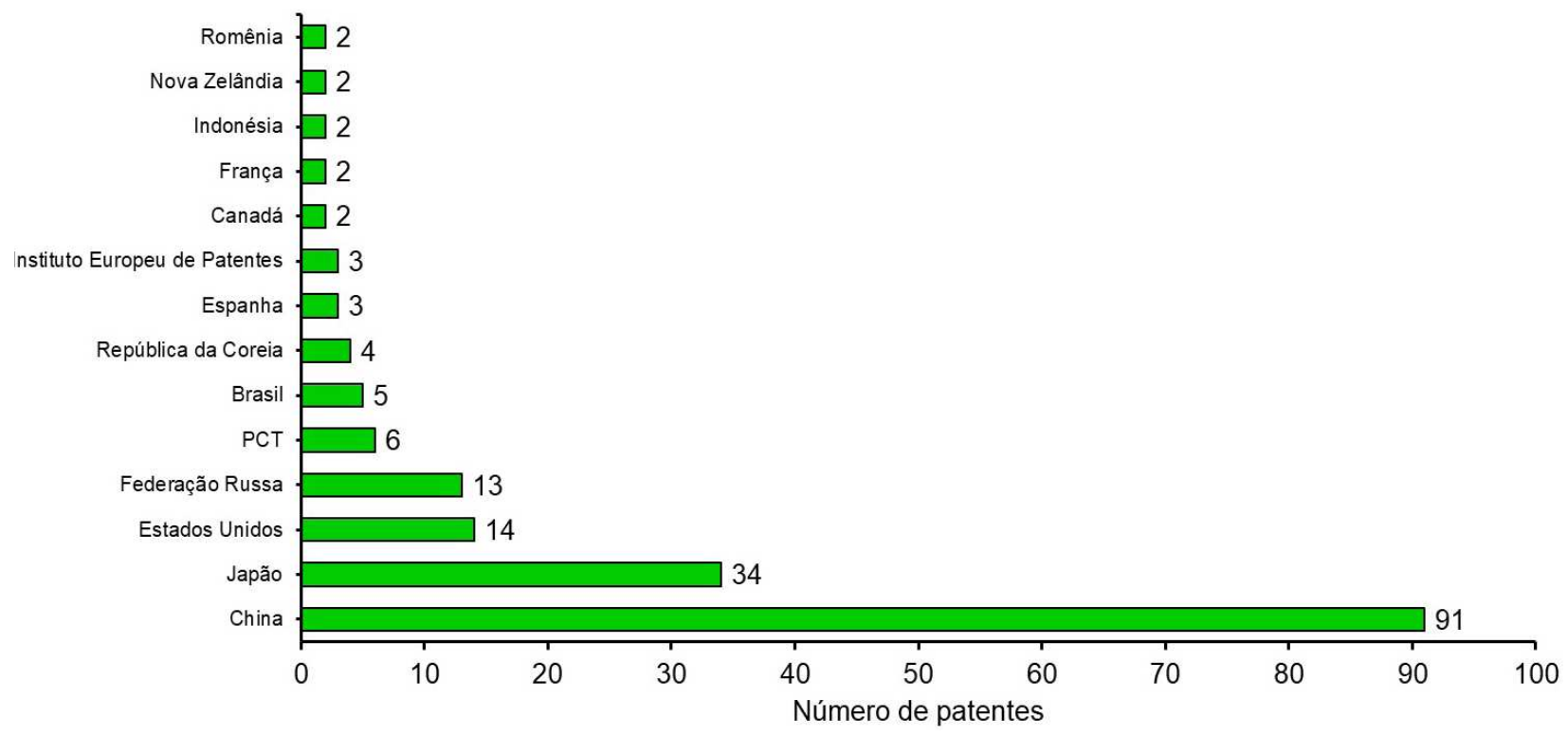

Fonte: Elaborada pelos autores deste artigo (2020)

De acordo com o Ministério da Agricultura do país, as grandes plantações são as principais fontes de contaminação da água da China, já que a imensa proporção do setor agrícola reflete uma dependência massiva do país por insumos artificiais, como os fertilizantes (ECODEBATE, 2010). Nesse sentido, a China pretende atingir zero crescimento na utilização de produtos químicos agrícolas este ano, para isso, o uso de biofertilizantes surge como alternativa para o desenvolvimento das lavouras.

Figura 2 - Anos com maior número de patentes retornados a partir de buscas na WIPO, INPI e Espacenet

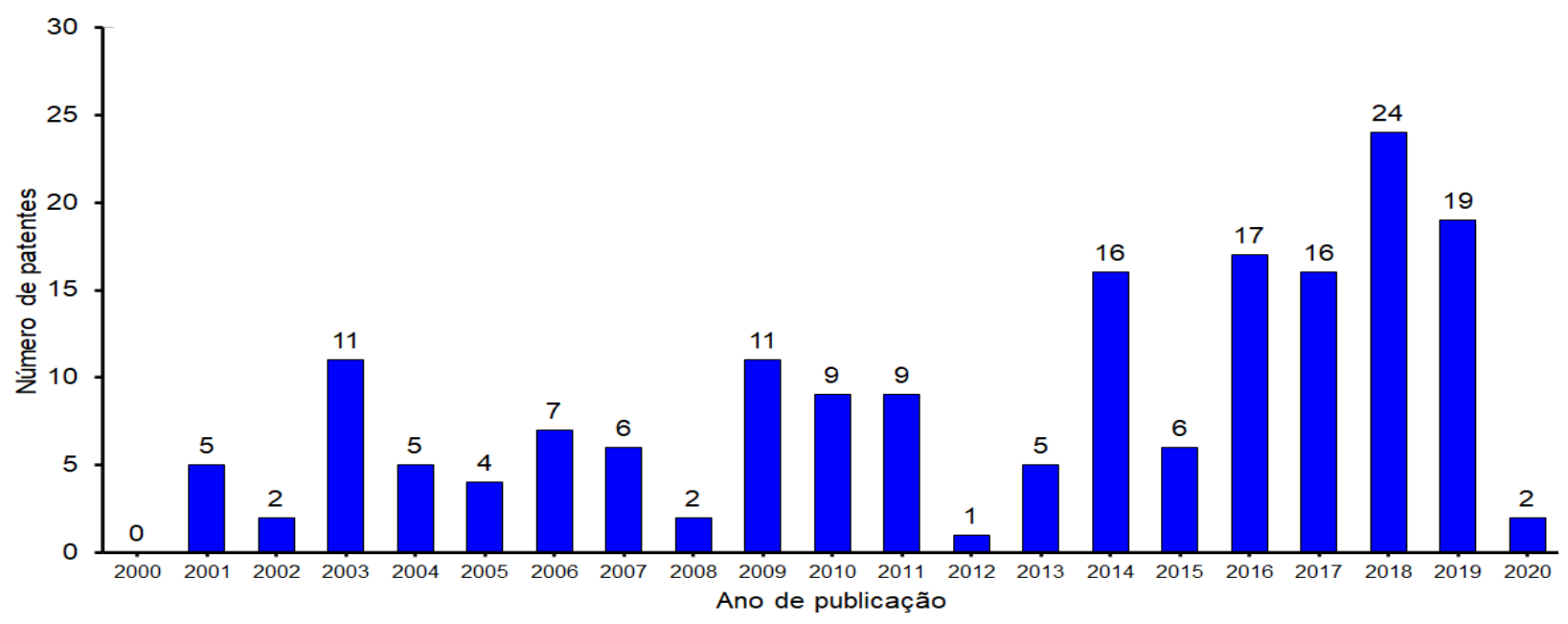

Fonte: Elaborada pelos autores deste artigo (2020) 
A busca por artigos também evidenciou uma pequena quantidade de trabalhos que abordam a aplicação das tecnologias estudadas em espécies leguminosas (Figura 3). Diante dos resultados obtidos em relação à busca de artigos, Brasil e Cuba são os países com maior número de publicações. Ressalta-se que os trabalhos se concentram na produção de diferentes espécies de feijão. Isso pode ser associado ao grande consumo desses alimentos em todo o mundo devido à sua composição nutricional, pois é uma rica fonte de proteínas e minerais como cálcio, ferro, fósforo, magnésio e zinco, além das vitaminas: tiamina, niacina e ácido fólico (ULLOA et al., 2011).

Figura 3 - Artigos de interesse nas bases Scielo e Periódicos/CAPES

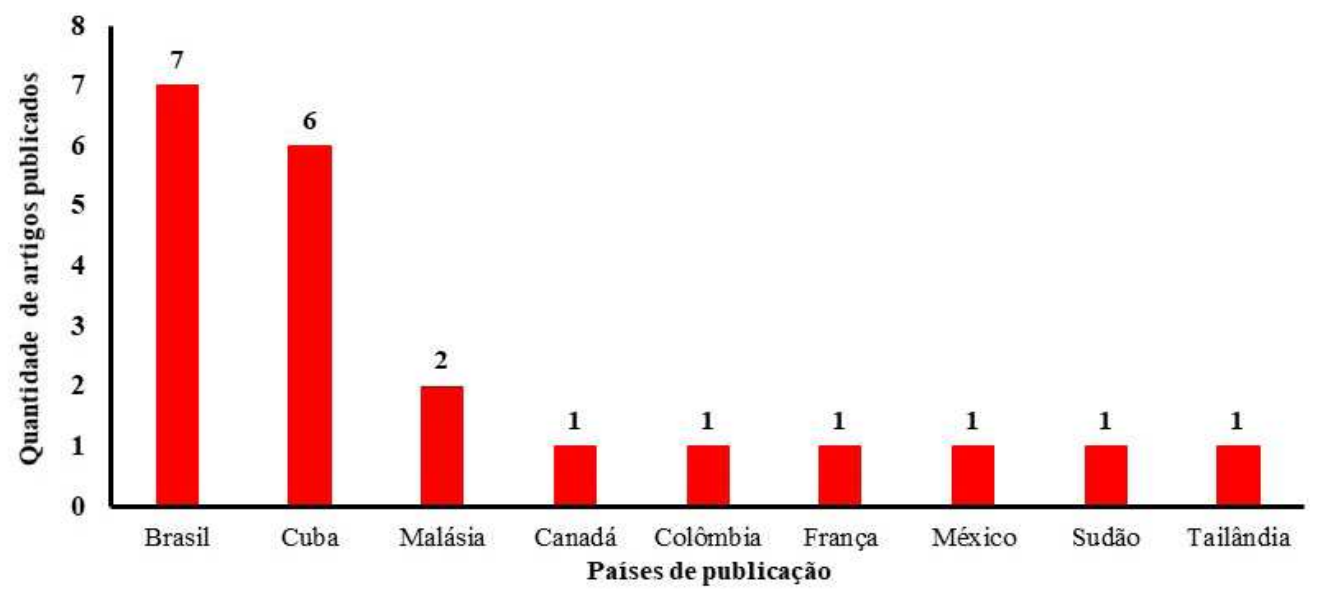

Fonte: Elaborada pelos autores deste artigo (2020)

Embora o Brasil seja um dos principais produtores (3,17 milhões de hectares na safra 2017/2018) e consumidores de feijão comum em todo o mundo, o rendimento de grãos é abaixo de $1.000 \mathrm{~kg} / \mathrm{ha}$, portanto, muitas estratégias foram consideradas para melhorar o rendimento a baixo custo, uma delas é a troca do uso de fertilizantes sintéticos por biofertilizantes (CONAB, 2019). De acordo com informações da CONAB, a primeira safra deste ano é estimada em 926,5 mil hectares, crescimento de $0,4 \%$ em relação à safra passada. A previsão de uma produtividade maior deverá resultar em uma produção de 1,07 milhão de toneladas, 8,3\% maior que na última safra. A organização e o intenso processo de modernização das cadeias produtivas do agronegócio fizeram com que os elos anteriores e posteriores às atividades agrícolas, como os de produção de insumos, processamento e distribuição, apresentassem importância cada vez maior no Produto Interno Bruto (PIB).

Em 2018, a agroindústria e os serviços empregaram, respectivamente, 4,12 milhões e 5,67 milhões de pessoas, enquanto 227,9 mil estavam ocupadas no segmento de insumos do agronegócio, demonstrando a ampliação do setor, o que gera uma maior movimentação de recursos financeiros e investimentos relacionados a tecnologias que o beneficiem (EMBRAPA, 2018).

Cuba é um dos raros oásis de agricultura orgânica e sustentável, por razões políticas, geográficas e filosóficas, o País foi forçado a abandonar grande parte de sua agricultura em larga escala e com ampla utilização de produtos químicos e substituí-la por uma rede de pequenas fazendas e métodos mais naturais. O País latino-americano cuja organização social e a base de produção de alimentos são pautadas no socialismo e na produção camponesa de alimentos tem buscado ao longo das últimas décadas atingir a Soberania alimentar, projetando novos tipos de fertilizantes (SOUSA, 2015; HERNÁNDEZ, 2008). 
O número de artigos sobre o tema é mínimo. Isso corrobora com o relato de Garrido (2018), que afirma o direcionamento desse tipo de conteúdo para o patenteamento. Ainda seguindo os conceitos do autor, as chamadas tecnologias verdes direcionam o desenvolvimento tecnológico e econômico no caminho da sustentabilidade, com incentivos à inovação nos negócios. O investimento tecnológico em patentes relacionadas a tais tecnologias demonstra a preocupação de países quanto à aplicação de conceitos de inovação na mudança do padrão de crescimento vigente, que prioriza um consumo desenfreado de insumos para máxima produção, ampliando, assim, o seu olhar para os aspectos de sustentabilidade, seja ela econômica, social ou ambiental.

De acordo com a Figura 4, verifica-se que o maior número de depositantes são pertencentes à China, a indústria de fertilizantes Qingdao Jiame Wang Fertilizer apresenta um total de 11 patentes de interesse, nota-se uma preocupação em desenvolver produtos que ajudem a adsorção de selênio, o que é importante, uma vez que o elemento proporciona associações com a glutationa peroxidase, ajudando a minimizar peróxidos da célula vegetal, bem como a aumentar a eficiência do metabolismo do nitrogênio em plantas.

Atualmente, a China é um dos países que mais cresce no mundo, no contexto econômico, industrial, financeiro, e está prestes a se tornar uma potência mundial. No contexto da produção tecnológica, o País possui maior contribuição de produção de patentes agrícolas, com vantagens tecnológicas em áreas como melhoramento e gerenciamento de animais, controle de pragas, máquinas e equipamentos agrícolas, nutrição e ração animal, nutrição de plantas e fertilizantes (GOTTEMS, 2019).

O processo de desenvolvimento de fertilizantes utilizados na produção agrícola ocasiona a emissão de óxido nitroso (NO) e, consequentemente, o aumento na quantidade dos gases de efeito estufa (WAYCARBON, 2017). Em paralelo, a sociedade demanda a adoção de soluções acessíveis e escaláveis em direção a uma sociedade mais limpa e a economias resilientes, com baixa utilização do carbono. Tais fatores são abordados no Acordo de Paris, assinado em 12 de dezembro de 2015 por 195 países durante a 21a Conferência das partes da convenção-quadro das Nações Unidas sobre a mudança do clima. O acordo passou a vigorar em 4 de novembro de 2016, tendo como meta a redução dos impactos com aumentos de temperatura menores que $2^{\circ} \mathrm{C}$, com esforços direcionados ao aumento de $1,5^{\circ} \mathrm{C}$. Por conseguinte, os países estão formulando estratégias para se adaptar aos cenários de mudanças climáticas, buscando novas tecnologias para reduzir as emissões de gases de efeito estufa e empenhando esforços para conseguir um desenvolvimento sustentável (GARRIDO, 2018). O que reforça a necessidade de pesquisas acerca da aplicação de biofertilizantes na produção agrícola como forma de minimizar os impactos desse setor da economia. 
Figura 4 - Principais depositantes de patentes retornados a partir de buscas na WIPO, INPI e Espacenet

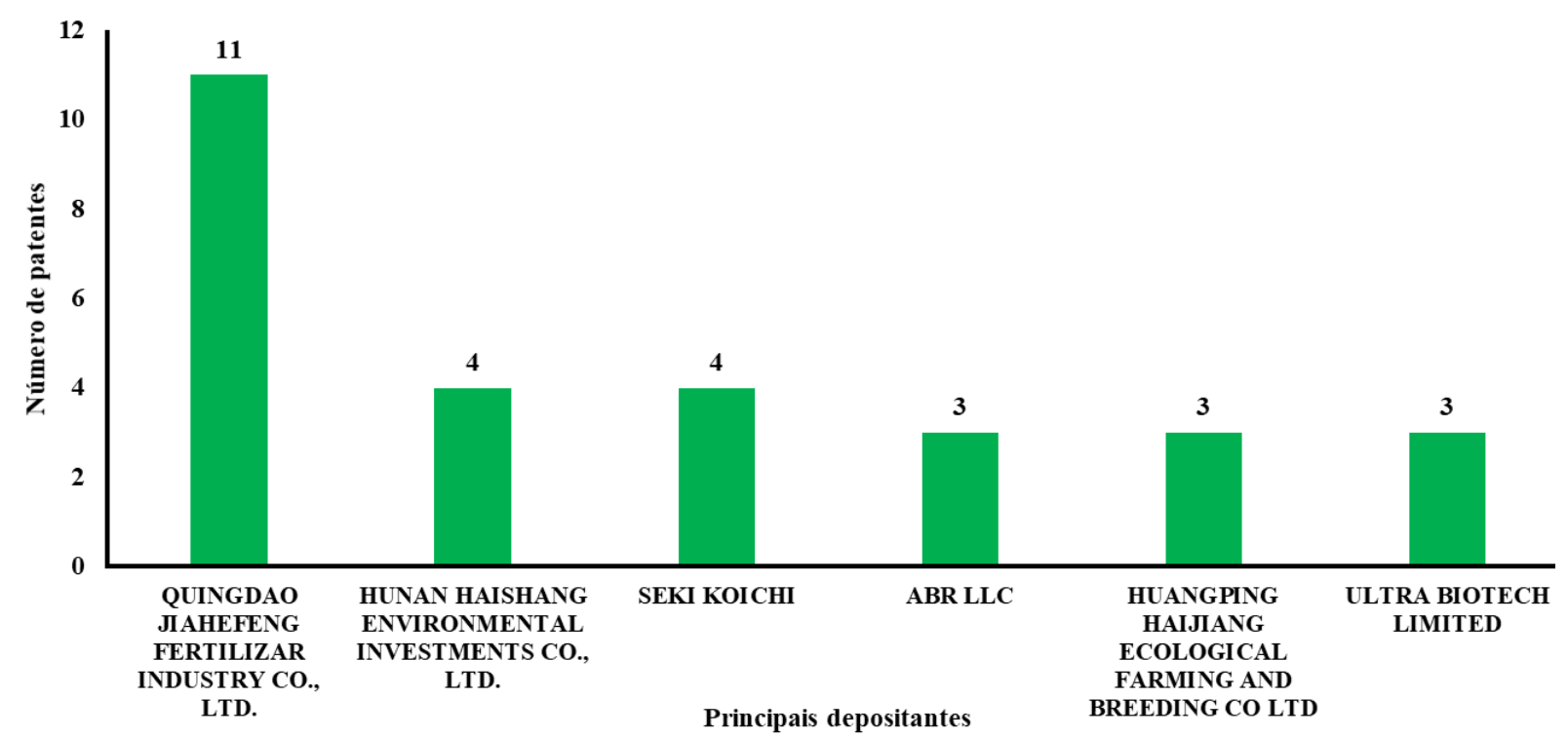

Fonte: Elaborada pelos autores deste artigo (2020)

O tamanho do mercado global de biofertilizantes foi avaliado em US $\$ 1,0$ bilhão em 2019 e é prevista uma taxa de crescimento anual composta (CAGR) de 12,8\% de 2020 a 2027. A adaptabilidade tecnológica vem com altos investimentos, o que, por sua vez, afeta o retorno geral dos aplicantes. Esse é um fator-chave que coloca uma barreira de entrada no ambiente competitivo global. Com várias empresas de milhões de dólares trabalhando no desenvolvimento de insumos agrícolas de alto desempenho, como fertilizantes e vários pesticidas, a necessidade de produtos alternativos e amigos do ambiente está no auge (GVR, 2019).

\subsection{Análise dos Trabalhos Publicados}

Entre os trabalhos apurados, a maioria é voltada para a produção e aplicação de fertilizantes orgânicos e microbianos destinados a qualquer cultivo agrícola (YUKIO et al., 2003; SOMEUS, 2004; NORIJI et al., 2011; RIN; ZEN; CHAR, 2010). Isso demonstra grande diversidade de matéria-prima e de desenvolvimento de métodos e/ou produtos que fazem uso de matéria animal. Os processos citam métodos de preparo de fertilizantes com excrementos humanos (MASAHIRO et al., 2002), esterco bovino (DONGPO; ZHIJIE, 2011), esterco de aves (SEIKI:KK; AKEMASA, 2003; HIROMI, 2003; TOSHIO, 2013), esterco suíno (DACHUN et al., 2015), estrume de ovelhas (AIMIN, 2015), resíduos do processamento de peixe (SINCLAIR, 1996), resíduos urbanos (MIRANDA, 2018), além de citar preparações com uso de matérias vegetais, como cana de açúcar, melaço, soja, farelo de arroz, milho, ureia e vários outros (NING; QIULIANG, 2017).

Grande parte dos materiais faz uso de comunidades de microrganismos, fungos, húmus de minhoca ou quaisquer comunidades de favoreçam a fermentação no processo de compostagem, os quais são resultantes da biodigestão de compostos orgânicos, alguns constituídos por uma variedade de espécies de microrganismos, que são considerados benéficos para o solo, pois 
possuem propriedades que ajudam as plantas a absorverem melhor os nutrientes presentes na terra e a aumentarem a concentração e a disponibilidade de certas substâncias, além disso, as bactérias presentes em fertilizantes microbianos aumentam a eficácia na absorção de N. Os métodos de fermentação adotados também são diversificados, alguns autores fazem uso da respiração anaeróbica, ou seja, sem uso de O (HOFF, 2018), e outros aeróbicos (CHA, 2011), atingindo os resultados esperados em ambos os casos.

O trabalho de Rin, Zen e Char (2010), por exemplo, aponta que os microrganismos Bacillus spp., Azotobacter spp., Trichoderma spp., Saccharomyces spp., ou a combinação deles, são benéficos ao crescimento das culturas em geral. O uso de microrganismos para o enriquecimento de nutrientes do solo também é descrito pelas patentes de Xiuwu (2019) e Nikolaevna et al. (2019), as quais fazem uso de bactérias do gênero Rhizobium que interagem com as plantas por meio de simbiose, contribuindo para a assimilação de nitrogênio. Entre elas, vale destacar o estudo do efeito conjunto de materiais orgânicos e bactérias por parte das patentes chinesas, cujo processo proposto por Xiuwu (2019) relata aumentos nos conteúdos de vitamina C, selênio e massa de grão no cultivo de amendoim.

A inoculação é descrita em alguns materiais que expõem formas de introduzir bactérias promovedoras de crescimento (DRADASAN et al., 2015) e fungos (NODA, 2009). Observa-se que a inovação é encontrada muito mais nos métodos que nos produtos, uma vez que o uso de material de origem animal e/ou vegetal fermentado ainda é predominante, porém, as formas de obtenção e de aplicação dos biofertilizantes são diversificadas e testam técnicas diferentes. Musa et al. (2011), por exemplo, avaliaram os efeitos da inoculação com estirpe de Bradyrhizobium, procedendo ao uso de sementes de feijão-caupi umedecidas e misturadas com o inóculo de Bradyrhizobium à base de carvão, o que levou a um aumento na produção de feijão.

Poucos são os trabalhos que delimitam o uso do produto apenas para leguminosas. As patentes de Timofeevna et al. (1998), Youguo, Huiming e Dasong (2018) e de Sheng (2016), por exemplo, descrevem métodos de inserção de culturas microbianas no cultivo de leguminosas com o intuito de aumentar o desenvolvimento e o rendimento desse cultivo. Alguns documentos indicam o cultivo de leguminosa ao qual o insumo deve ser inserido, sendo estes: Chenglong, Hua e Zhou (2019) (amendoim); Nikolaevna et al. (2019) (ervilhas); Yaroslavovych, Mykhailivna e Dmytriivna (2008); González et al. (2017); González et al. (2016); Batista et al. (2017) (feijão); Hairu e Yanxin (2017) (sorgo); Dradasan et al. (2015) (alfafa); e Sánchez-Yáñez et al. (2014) (grão de bico).

A população microbiana presente na rizosfera é relativamente diferente daquela do seu entorno, devido à presença de exsudatos radiculares que funcionam como fonte de nutrientes para o crescimento microbiano (BURDMAN; JURKEVITCH; OKON, 2000). As rizobactérias são um exemplo de microrganismos encontrados dentro da rizosfera, ou seja, no ambiente do solo onde a raiz da planta está disponível, uma zona de atividade microbiana máxima, resultando em um nutriente confinado do qual são extraídos macro e micronutrientes essenciais (AHMAD; AHMAD; KHAN, 2008). Essas associações promovem um aumento no volume da raiz, permitindo uma maior exploração da rizosfera, e são consideradas os componentes mais ativos dos órgãos de absorção de nutrientes da planta, que, por sua vez, fornecem aos fungos nutrientes 
orgânicos e um nicho protetor (ANTONIOLLI; KAMINSKI, 1992). O estudo realizado por Keshavarz, Chaichi e Moghadam (2012) mostrou que a aplicação desses microrganismos como inoculantes de sementes resultou em maior produtividade e qualidade em diferentes culturas. Efeito também observado no trabalho desenvolvido por uma equipe do Instituto Internacional de Pesquisa em Cultivos para os Trópicos Semiáridos que obteve resultados positivos com a inoculação de actinobactérias como biofertilizante em cultivos de milho (SATHYA; VIJAYABHARATHI; GOPALAKRISHNAN, 2017).

\section{Considerações Finais}

A China figura como o país com maior produção de tecnologias na área, o que é atribuído a suas políticas sociais com relação ao uso de agroquímicos, associado à sua cultura de inovação e densidade populacional que induzem a busca por tecnologias destinadas ao aumento do rendimento em sua produção agrícola.

A análise dos artigos evidenciou uma quantidade mínima de trabalhos que abordam a aplicação das tecnologias estudadas em espécies leguminosas. Brasil e Cuba destacam-se com uma maior porcentagem de artigos, as pesquisas se concentram na produção de diferentes espécies de feijão. Embora sejam abordadas diferentes tecnologias de melhoramento para a produção de leguminosas com ênfase na sustentabilidade, a quantidade de trabalhos ainda é considerada mínima e requer mais exploração, tanto dos novos métodos como também em relação ao estudo da aplicação nas diversas espécies de leguminosas.

Diante da importância comercial e nutricional das leguminosas, a produção de biofertilizantes para a inserção em seus cultivos é incipiente, limitando-se a poucos estudos envolvendo tecnologias que fazem o uso de microrganismos relacionados à absorção de nitrogênio, fósforo $e$ outros nutrientes. Nesse segmento, ainda há a necessidade de realização de mais estudos acerca do efeito conjunto do uso de microrganismos com outras matérias-primas orgânicas utilizadas no preparo de biofertilizantes, além da produção de tecnologias específicas para algumas culturas, o que pode vir a contribuir ainda mais com a eficiência de produção.

\section{Perspectivas Futuras}

Diante do que foi exposto, ressalta-se que um caminho para futuras pesquisas deve ser desenvolver biofertilizantes que sejam minuciosamente desenvolvidos apenas para leguminosas ou para alguma espécie leguminosa em específico. Os trabalhos que descrevem técnicas das quais a inoculação microbiana façam parte do processo é uma alternativa a se pensar, uma vez que faz parte das estratégias mais inovadoras nesse ramo. Outra alternativa pode ser a técnica de manejo denominada simbiose micorrízica, que também é pouco explorada e pode ser usada com a inoculação microbiana. Registra-se que a técnica simbiose micorrízica aumenta significativamente a absorção de nutrientes como nitrogênio, potássio, cálcio, zinco, magnésio e, especialmente, fósforo, além de melhorar o transporte e a absorção de água no vegetal e criar uma certa resistência da planta hospedeira à seca (AL-KARAKI; CLARK, 2008). 


\section{Referências}

ABSOLO. China planeja substituir fertilizantes químicos por nutrientes orgânicos. [2017]. Disponível em: Disponível em: https://abisolo.com.br/2017/10/17/china-planeja-substituirfertilizantes-quimicos-por-nutrientes-organicos/. Acesso em: 6 abr. 2020.

AHMAD, F; AHMAD, I.; KHAN, M. S. Screening of free-living rhizospheric bacteria for their multiple plant growth promoting activities. Microbiological Research, [s.l.], Elsevier BV, v. 163, n. 2, p. 173181, mar. 2008. DOI: https://doi.org.org/10.1016/j.micres.2006.04.001.

AIMIN, Z. Manufacture and use an organic nutrition soil for growing organic plants. Titular: Zhang Aimin. SG n. SG2013095849. Depósito: 26 2013. Concessão: 30 jul. 2015.

ALDKARAKI, G. N.; CLARK, R. B. Growth, mineral acquisition, and water use by mycorrhizal wheat grown under water stress. Journal of Plant Nutrition, [s.l.], v. 21, p. 263-276, nov. 2008.

ARAÚJO, J. F.; GOMES, Í. L. S.; SOUZA, G. N. de. Utilização de fontes alternativas de adubos orgânicos e minerais naturais. 5. ed. Salvador: Editora da Universidade do Estado da Bahia, 2014. 40p.

AMBROSIO, R.; ORTIZ-MARQUEZ, J. C. F; CURATTI, L. Metabolic engineering of a diazotrophic bacterium improves ammonium release and biofertilization of plants and microalgae. Metabolic Engineering, [s.l.], v. 40, p. 59-68, mar. 2017.

ANTONIOLLI, Z. I.; KAMINSKI, J. Micorrizas. Ciência Rural, Santa Maria, RS, v. 21, n. 3, p. 441455, mar. 1992.

BATISTA, É. R. et al. Combined inoculation of rhizobia on the cowpea development in the soil of Cerrado. Ciências Agronômicas, Fortaleza, p. 745-755, out. 2017.

BLAISE, D. et al. Effects of farmyard manure and fertilizers on yield, fibre quality and nutrient balance of rainfed cotton (Gossypium hirsutum). Bioresource Technology, [s.l.], v. 96, n. 3, p. 345349, 2005.

BURDMAN, S.; JURKEVITCH, E.; OKON, Y. Recent advances in the use of plant growth promoting rhizobacteria (PGPR) in agriculture. Microbial Interactions in Agriculture and Forestry, [s.l.], v. 2, p. 229-250, 2000.

BUSINESS WIRE. Global Biofertilizer Market 2016-2020: Main Growth Driver is Affordable Cost of Bio Fertilizers - Research and Markets. [2018]. Disponível em: https:/www.businesswire.com/ news/home/20160426005882/en/Global-Biofertilizer-Market-2016-2020---Main-Growth. Acesso em: 16 nov. 2020.

CAPES - COORDENAÇÃO DE APERFEIÇOAMENTO DE PESSOAL DE NÍVEL SUPERIOR. Portal de Periódicos. 2020. Disponível em: https://www.periodicos.capes.gov.br. Acesso em: 17 abr. 2020.

CHA, S. W. Method for manufacturing liquid fertilizer based on aerobic fermentation and a method for growing crops based on the liquid fertilizer capable of improving the quality of the liquid fertilizer by searching adequate fermenting conditions. Titular: Sang Wha Cha. KR n. KR1020110129613. Depósito: 26 maio 2010. Concessão: 2 dez. 2011.

CHENGLONG, H.; HUA, C.; ZHOU, E. Organic fertilizer containing leguminous plants, and preparation method of organic fertilizer. Depositante: Zunyi Nongshen Industry Limited Company. CN n. CN109111284. Depósito: 5 set. 2018. Concessão: 1º jan. 2019. 
CHAOBAO, Z. Preparation method of peanut high yield fertilizer. Titular: Zhu Chaobao. CN n. CN101575237. Depósito: 9 maio 2008. Concessão: 11 nov. 2009.

\section{CONAB - COMPANHIA NACIONAL DE ABASTECIMENTO. Acompanhamento da Safra} Brasileira Grãos: safra 2018/2019. Brasília, DF: Conab, 2019. v 6. ISSN: 2318-6852

DACHUN, J. et al. Pig farm manure field ecological recycling system. Titular: Wenzhou Vocational College Of Science and Technology. CN n. CN204434431. Depósito: 3 fev. 2015. Concessão: $1^{\circ}$ jul. 2015.

DADRASAN, M. et al. Deficit irrigation and biological fertilizer influence on yield and trigonelline production of fenugreek. Industrial Crops and Products, [s.l.], v. 77, p. 156-162, dez. 2015.

DONGPO, L.; ZHIJIE, W. Fertilizer taking maize straw abdomen-passing product as carrier, preparation method thereof and application thereof. Depositante: Institute of Applied Ecology, China Academy Of Sciences. CN n. CN102115351. Depósito: 30 dez. 2009. Concessão: 6 jul. 2011.

ECODEBATE. Produção agropecuária é a maior responsável pela poluição da água na China. [2010]. Disponível em: https://www.ecodebate.com.br/2010/02/10/producao-agropecuaria-e-amaior-responsavel-pela-poluicao-da-agua-na-china/. Acesso em: 6 abr. 2020.

EMBRAPA - EMPRESA BRASILEIRA DE PESQUISA AGROPECUÁRIA. Trajetória da agricultura brasileira. 2018. Disponível em: https://www.embrapa.br/visao/trajetoria-da-agricultura-brasileira. Acesso em: 7 abr. 2020.

ESPACENET. European Patent Office. 2020. Disponível em: https://pt.espacenet.com/?locale=pt_ PT. Acesso em: 20 mar. 2020.

FREIRE FILHO, F. R. Feijão-Caupi no Brasil. Teresina: Embrapa Meio-Norte, 2017. 84p.

GARRIDO, E. C. Potencial de negócios em patentes verdes: foco em tecnologias para produção de biofertilizantes. 2018. 96p. Dissertação (Mestrado em Propriedade Intelectual e Transferência de Tecnologia para Inovação) - PROFNIT, Universidade Federal da Bahia, Bahia, 2018.

GONZÁLEZ, L. M. et al. Efecto de productos bioactivos en plantas de frijol (Phaseolus vulgaris L.) Biofertilizadas. Cultivos Tropicales, [s.l.], v. 37, n. 3, p. 165-171, 2016.

GONZÁLEZ, L. M. et al. Efecto de bioestimulantes en el rendimiento de dos cultivares de frijol (Phaseolus vulgaris L.) Biofertilizados. Cultivos Tropicales, [s.l.], v. 38, n. 2, p. 113-118, 2017.

GOTTEMS, L. Ciência agrícola da China ocupa o segundo lugar no mundo: análise foi feita pela Academia Chinesa de Ciências Agrícolas. 2019. Disponível em: https://www.agrolink.com.br/ noticias/ciencia-agricola-da-china-ocupa-o-segundo-lugar-no-mundo_426758.html. Acesso em: 12 abr. 2020.

GVR - GRAND VIEW RESEARCH. Biofertilizers Market Size, Share \& Trends Analysis Report By Product (Nitrogen Fixing, Phosphate Solubilizing), By Application (Seed Treatment, Soil Treatment), By Crop Type, By Region, And Segment Forecasts, 2020-2027. 2019. Disponível em: https://www.grandviewresearch.com/industry-analysis/biofertilizers-industry. Acesso em: 26 jul. 2020. 
HAIRU, J.; YANXIN, W. Application of vinasse in promoting growth of sorghum and application method thereof. Titular: Zhejiang Normal University. CN n. CN106717782. Depósito: 23 nov. 2016. Concessão: 31 maio 2017.

HERNÁNDEZ, M. I. et al. Evaluación agronómica de fertilizantes líquidos cubanos en el cultivo protegido del tomate (solanum lycopersicum 1.) Hibrido ha 3019. Cultivos Tropicales, Habana, v. 29, p. 73-81, mar. 2008.

HIROMI, S. Method for producing liquid fertilizer, method for producing compost and no-tillage farming method. Titular: Someya:kk. JP n. JP2013159535. Depósito: 7 fev. 2002. Concessão: 19 ago. 2003.

HOFF, S. K. Methods for upgrading spent biomass material. Titular: Advanced Substrate Technologies A/s. US n. US20180111884. Depósito: 21 jan. 2016. Concessão: 26 abr. 2018.

IGIEHON, N. O.; BABALOLA, O. O. Biofertilizers and sustainable agriculture: exploring arbuscular mycorrhizal fungi: exploring arbuscular mycorrhizal fungi. Applied Microbiology and Biotechnology, [s.l.], v. 101, n. 12, p. 4.871-4.881, maio 2017.

INPI - INSTITUTO NACIONAL DA PROPRIEDADE INDUSTRIAL. 2020. Disponível em: http:// www.inpi.gov.br/. Acesso em: 18 mar. 2020.

KESHAVARZ, A. R.; CHAICHI, M. R.; MOGHADAM, H. Irrigation, Phosphorus Fertilizer and Phosphorus Solubilizing Microorganism Effects on Yield and Forage Quality of Turnip (Brassica rapa L.) in an Arid Region of Iran. Agricultural Research, [s.l.], v. 1, n. 4, p. 370-378, 2012.

MASAHIRO, Y. et al. Circulating network system in home. Depositante: Matsushita Electric Ind Co Ltd. JP n. JP2002345338. Depósito: 25 maio 2001. Concessão: 13 fev. 2002.

MIRANDA, J. F. de. Produção de fertilizante(s) organomineral(is) a partir dos resíduos sólidos urbanos e outros resíduos orgânicos, incluindo fezes de animais domésticos e de criação industrial. Titular: José Francisco de Miranda. BR n. BR102017007695. Depósito: 13 abr. 2017. Concessão: 26 jun. 2018.

MUSA, E. M. et al. Effect of intercropping, Bradyrhizobium inoculation and N, P fertilizers on yields, physical and chemical quality of cowpea seeds. Frontiers of Agriculture in China, [s.l.], v. 5, n. 4, p. 543-551, dez. 2011.

NIKOLAEVNA, R. V. et al. Strain of rhizobium leguminosarum bv viceae bacteria for producing bacterial fertilizer for pea. Depositante: Nstitut Mikrobiologii I Virusologii Im.D.K.Zabolotnogo. SU n. SU01824384. Depósito: 31 jan. 1990. Concessão: 30 jun. 1993. 2019.

NING, Z.; QIULIANG, C. Culture substrate of vegetables and preparing method and cultivating method thereof. Titular: Minnan Normal University. CN n. CN107306780. Depósito: 21 jul. 2017. Concessão: 3 nov. 2017.

NODA, Y. Las Micorrizas: una alternativa de fertilización ecológica en los pastos. Pastos y Forrajes, [s.l.], v. 32, n. 2, p. 1-1, fev. 2009.

NORIJI, A. E. et al. Liquid fertilize. Depositante: Sumitomo Chemical Co Ltd. JP2011105541. Concenssão: 2 jun. 2011.

NUNNERY, J. K.; MEVERS, E.; GERWICK, W. H. Biologically active secondary metabolites from marine cyanobacteria. Current Opinion in Biotechnology, [s.l.], Elsevier BV, v. 21, n. 6, p. 787793, dez. 2010. 
PRAKASH, J.; ARORA, N. K. Development of Bacillus safensis-based liquid bioformulation to augment growth, stevioside content, and nutrient uptake in Stevia rebaudiana. World Journal of Microbiology and Biotechnology, [s.l.], v. 36, n. 1, p. 1-13, 19 dez. 2019.

RIN, J.; ZEN, W. S. S.; CHAR, K. To promote the growth of a plant microbial formulations and methods for using the same. Depositante: Ultra Bio Technology. JP n. JP2010530350. Depósito: 2 jun. 2008. Concessão: 9 set. 2010.

SÁNCHEZ-YÁÑEZ, J. M. et al. Respuesta del garbanzo (Cicer arietinum L.) a la inoculación con Azotobacter vineladii y Burkholderia cepacia a dosis reducida de fertilizante nitrogenado. Scientia Agropecuaria, [s.l.], v. 5, n. 3, p. 115-120, 2014.

SATHYA, A.; VIJAYABHARATHI, R.; GOPALAKRISHNAN, S. Actinobactérias promotoras de crescimento de plantas: uma nova estratégia para melhorar a produção sustentável e a proteção de leguminosas para grão. 3 Biotech, [s.l.], v. 7, n. 2, p. 1-10, 2017.

SCIELO. Scientific Eletronic Library Online. 2020. Disponível em: https://scielo.org/. Acesso em: 2 jul. 2020.

SEIKI:KK, K.; AKEMASA, N. Método para planta de cultivação. JP n. JP2003116339. Depósito: 18 out. 2001. Concessão: 22 abr. 2003.

SHENG, W. Compound fertilizer special for leguminous plants in saline-alkali soil and production method of compound fertilizer. Depositante: Shandong Sunway Landscape Technology Co., Ltd. CN n. CN106220362. Depósito: 29 jul. 2016. Concessão: 14 dez. 2016.

SINCLAIR, C. P. Improvements in and relating to liquid fertilisers including fungi, microorganisms, and reproductive material therefor. Titular: Sieber Technology Limited. NZ n. NZ248768. Depósito: 26 set. 1994. Concessão: 20 dez. 1996.

SOMEUS, E. Solid carrier based microbial inoculants and method for manufacturing of such product. Titular: Edward Someus. US n. US20060243011. Depósito: 23 jun. 2004. Concessão: 29 dez. 2004.

SOUSA, R. Agroecologia como possibilidade de uma soberania alimentar: um olhar a partir de Cuba. [S.l.: s.n.], 2015. 13p.

TIMOFEEVNA, N. A. et al. Strain of rhilobium leguminosarum tuber bacteria for producing bacterial fertilizer for lens. RU n. SU01446132. Depósito: 6 nov. 1986. Concessão: 23 dez. 1988.

TOSHIO, F. Fertilizante de gota galinha roasted. Titular: Fukutomi Toshio. JP n. JP2013006754. Depósito: 23 jun. 2011. Concessão: $1^{\circ}$ out. 2013.

ULLOA, J. A. et al. El frijol (Phaseolus vulgaris): su importancia nutricional y como fuente de fitoquímicos. CONACYT, [s.l.], 2011.

VASSILEV, N. et al. Unexploited potential of some biotechnological techniques for biofertilizer production and formulation. Applied Microbiology and Biotechnology, [s.l.], v. 99, n. 12, p. 4.983-4.996, 2015.

WAYCARBON. 5 Fontes de Gases de Efeito Estufa que merecem a sua atenção. 2017.

Disponível em: https://blog.waycarbon.com/2017/02/5-fontes-de-gases-de-efeito-estufa/. Acesso em: 14 abr. 2020. 
WIPO - WORLD INTELLECTUAL PROPERTY ORGANIZATION, 2020. Disponível em: https:// patentscope.wipo.int/search/en/search.jsf Acesso em: 10 mar. 2020.

XIUWU, Z. Fertilizer applying method for improving peanut quality. Titular: Zhu Xiuwu. CN n. CN109121624. Depósito: 7 ago. 2018. Concessão: 4 jan. 2019.

YAROSLAVOVYCH, K. S.; MYKHAILIVNA, M. N.; DMYTRIIVNA, K. O. Bacteria strain rhizobium leguminosarum bv. Viceae $\mathrm{m} 1$ for preparation of bacterial fertilizer for pea. Titular: Inst of Plant Physiology and G. UA n. UA81577. Depósito: 30 jan. 2006. Concessão: 10 jan. 2008.

YOUGUO, L.; HUIMING, L.; DASONG, C. Complex microbial inoculant with plant growth promoting and yield improving effects on leguminous plants and application of complex microbial inoculant. CN n. CN108624528. Depósito: 14 maio 2018. Concessão: 9 out. 2018.

YUKIO, K. et al. Growth accelerator for plant. Depositante: Toho Leo Co. JP n. JP2003192484. Depósito: 27 dez. 2001. Concessão: 9 set. 2003.

\section{Sobre os Autores}

\section{Erika Matias da Silva}

E-mail: erika.matias@outlook.com

ORCID: http://orcid.org/0000-0002-5245-0201

Graduanda de Licenciatura em Química pela Universidade Estadual de alagoas.

Endereço profissional: Universidade Estadual de Alagoas, Rodovia AL-115, km 03, Palmeira dos Índios, AL. CEP: 57604-595.

\section{Adrielle Firmino da Silva}

E-mail: adriellequimica2019@gmail.com

ORCID: http://orcid.org/0000-0002-1817-3722

Graduanda de Licenciatura em Química pela Universidade Estadual de Alagoas.

Endereço profissional: Universidade Estadual de Alagoas, Rodovia AL-115, km 03, Palmeira dos Índios, AL. CEP: 57604-595.

\section{Jenivaldo Lisboa de Araújo}

E-mail: jenivaldochemscience@gmail.com

ORCID: http://orcid.org/0000-0002-1436-5401

Doutor em Química e Biotecnologia pela Universidade Federal de Alagoas em 2018.

Endereço profissional: Escola Estadual Muniz Falcão, Av. Cel. Clarindo Amorim, Cacimbinhas, AL. CEP: 57570-000. 